\title{
Synthesis, Solid and Solution Studies of Paraquat Dichloride Calixarene Complexes. Molecular Modelling
}

\author{
Irma García-Sosa and Flor de María Ramírez* \\ Instituto Nacional de Investigaciones Nucleares, Departamento de Química, Carretera México-Toluca S/N. La Marquesa, \\ Ocoyoacac. C.P. 52750, México. Phone: (+) 53297200. FAX: (+) 53297301. flor.ramirez@inin.gob.mx.
}

\begin{abstract}
The interaction of the herbicide paraquat dichloride (PQ, substrate) with $p$-tert-butylcalix[6,8]arenes ( $\mathrm{L}$, receptor) was investigated in both the solution and solid states. The isolated paraquat calixarene complexes were characterised by UV-visible, ${ }^{1} \mathrm{H}$ NMR, ESI-MS, Luminescence and IR spectroscopies and elemental analysis. The stoichiometry of complexes $\mathbf{1}$ and $\mathbf{2}$ was 1:1 (1 herbicide: 1 calixarene) and both revealed a biexponential luminescence decay with lifetimes depending on the size and the conformational particularity of the calixarenes. Molecular modelling suggested that both calixarenes interact with the herbicide through cation- $\pi$ interaction. PQ is included in the $p$-tert-butylcalix[8]arene cavity, a situation favoured by its pinched conformation in polar solvent while it is partially included in the $p$-tert-butylcalix[6]arene cavity because of its in-out cone conformation. The theoretical results, in particular using MOPAC procedures, were in agreement with the experimental findings.

Keywords: Parent calixarenes; Pesticides; Phosphorescence; Augmented Molecular Mechanics Calculations; CONFLEX.
\end{abstract}

\section{Introduction}

The introduction of the herbicide paraquat dichloride (PQ) to agriculture in the early 1960 's greatly facilitated weed control in crops [1]. Weeds that give shade to crops take their water and nutrients thus making harvesting difficult for more than 100 crops, for instance, corn, rice, wheat, apples, bananas, oranges, coffee, tea, cocoa and processed crops: cotton, sugar and rubber. Therefore, this herbicide is one of the most widely used in over 120 developed and developing countries.

The exposure to this herbicide through ingestion, inhalation or skin contact can, in the long term, lead to kidney, liver and heart problems as well as the scarring of the lungs and a narrowing of the esophagus [2]. Since there is no antidote to reverse the effects of this chemical on the human body, the current use of paraquat results in a health risk. Although the behaviour and properties of PQ in soils and plants have limited the interest in the research concerning procedures for its treatment, the research on paraquat from the chemical and environmental remediation points of view is of current interest: for example, alternatives for its adsorption [3] or immobilization [4] have been studied.

From the point of view of supramolecular chemistry, a variety of Quats belonging to the viologen family, such as the paraquat dichloride and paraquat derivatives, are considered interesting guests since they can be used as electron carriers as
Resumen. Se investigó la interacción del herbicida dicloruro de paraquat (PQ, substrato) con el $p$-ter-butilocalix $[6,8]$ areno (L, receptor) en el estado sólido y solución. Se aislaron los complejos calixarénicos de paraquat y se caracterizaron por espectroscopias de UVvisible, IR, RMN de hidrógeno, masas-ESI, Luminiscencia, IR y análisis elemental. La estequiometría de los complejos $\mathbf{1}$ y $\mathbf{2}$ fue 1:1 (1PQ:1 calixarene) y el decaimiento de luminiscencia en ambos casos fue bi-exponencial con tiempos de vidas dependientes del tamaño y la conformación del calixareno. El modelado molecular sugirió que ambos calixarenos interaccionan con el herbicida mediante interacción del tipo catión- $\pi$. PQ se incluye en la cavidad del p-ter-butilocalix[8]areno, situación que se favorece por su conformación "pinched" en un solvente polar mientras que en el p-terbutilocalix[6]areno se incluye parcialmente debido a su conformación de cono "in-out". Los resultados teóricos, en particular, procedimientos MOPAC, concordaron con los experimentales.

Palabras clave: Calixarenos padres, Plaguicidas, Fosforescencia, Cálculos de Mecánica Molecular Aumentado, CONFLEX.

well as for electrochromic transfer, the photochemical energy storage process, solar energy conversion and molecular electronic devices [5]. Calixarenes are highly versatile synthetic molecules capable of recognising charged and uncharged organic molecules [6]. The tri-dimensional topology of these organic macrocycles is revealed in a hydrophobic cavity and two rims of different size and polarity; their ability to behave as molecular baskets is still being investigated. Quats (quaternary ions) are recognised by negatively charged and neutral calixarenes receptors where cation (from the substrate) $-\pi$ (from the receptor) interactions have been shown to be the main driving force for their association [6, 7].

A considerable amount of work has been carried out on viologen-macromolecule complexes [7-9]. Calixarene-based pseudorotaxanes or calixarene-based rotaxanes formed with paraquat derivatives have been studied over the last ten years [10].

To the best of our knowledge, the formation of paraquat dichloride complexes with parent calixarenes, paratert-butylcalix [ $n]$ arenes with $n=4-20$ [6e] has not yet been explored. Since these calixarenes are able to act as receptors towards organic substrates such as organic cations by molecular recognition [6] where cation $-\pi$ interactions can occur with quaternary ions $[6,7]$, it was assumed that the receptors, para-tert-butylcalix[6] arene $\left(\mathrm{H}_{6} \mathrm{bL}^{6}\right)$ and paratert-butylcalix[8]arene $\left(\mathrm{H}_{8} \mathrm{bL}^{8}\right)$ would be able to recognise 


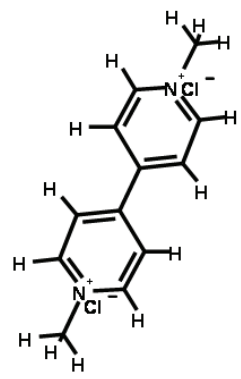

Paraquat dichloride

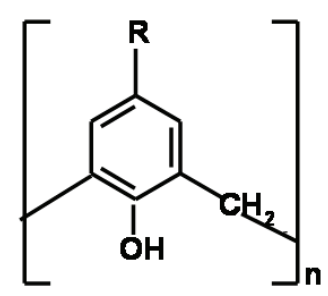

Calixarenes $\mathrm{n}=6,8 ; \mathrm{R}=$ tert-butyl groups
Scheme 1

the substrate, which is the herbicide paraquat dichloride (PQ) (Scheme 1) because of their size, conformation and $\pi$-base hydrophobic cavity $[6 \mathrm{~b}, 7 \mathrm{c}]$.

Therefore, the aims of this study were a) to investigate, by molecular modelling, the viability of the formation of paraquat-calixarene complexes through cation- $\pi$ interactions using the MOPAC quantum-mechanical procedures, b) to design a methodology for the synthesis of PQ-calixarene molecular complexes taking into account these theoretical results and c) to characterise the complexes and to study their stabilities in the solution and solid states by spectroscopic techniques.

\section{Results and Discussion}

\section{Synthesis and characterisation of paraquat calixarene molecular complexes}

Preliminary results from the interaction of $1 \times 10^{-4} \mathrm{M}$ of the substrate paraquat in isopropanol and $1 \times 10^{-4} \mathrm{M}$ of the receptors $\mathrm{H}_{6} \mathrm{bL}^{6}$ and $\mathrm{H}_{8} \mathrm{bL}^{8}$ in chloroform, together with the theoretical results discussed below, permitted the design and establishment of the methodology to synthesise the paraquat calixarene complexes.

The procedure for the synthesis of the paraquat para-tertbutylcalix $[n=6,8]$ arene complexes in sizable amounts was established. The reaction yield for the complex formed with para-tert-butylcalix[8] arene was 19\% larger than that with para-tert-butylcalix[6]arene.

The elemental analysis and NAA (Neutron Activation Analysis) of the isolated complexes yielded the minimum formulae: 1PQ:1para-tert-butylcalix [6] arene $\bullet \mathrm{H}_{2} \mathrm{O} \cdot \mathrm{CHCl}_{3}$, (compd. 1) and 1PQ:1 para-tert-butylcalix [8]arene $\bullet \mathrm{H}_{2} \mathrm{O}$ (compd. 2) which evidenced 1 herbicide: 1 calixarene stoichiometry. In the solid state, both compounds were yellowish, but in solution (chloroform-acetonitrile, v/v: 1:1.2) no colour was observed.

The UV-visible spectra of the $2-3 \times 10^{-5} \mathrm{M}$ solution of the compds. 1 and $\mathbf{2}$ in chloroform-acetonitrile mixture (v/v, $1: 1.2)$ showed neither the absorption band $\left(\delta_{\max } 396 \mathrm{~nm}\right)$ nor the typical yellow colour observed for paraquat macrocyclic complexes which had been reported to be due to charge transfer between the electron-rich aromatic rings of the receptor and the electron-poor pyridinium rings of the paraquat [6a, $6 b, 9 c]$. Significant spectral changes (Fig. 1) and a substantial increase in the molar absorption coefficients of both complexes, $\varepsilon\left(\mathrm{M}^{-1} \mathrm{~cm}^{-1}\right)$ : 28827 and 26267 at 278 and $286 \mathrm{~nm}$, respectively for $\mathbf{1}$, and 27140 and 30441 at $282 \mathrm{~nm}$ and 290 $\mathrm{nm}$ for $\mathbf{2}$ were observed with respect to the spectra and molar absorption coefficients of the free PQ (15721 M-1 $\mathrm{cm}^{-1}$ (260 $\mathrm{nm})$ and of the calixarenes $\mathrm{H}_{6} \mathrm{bL}^{6}(6225$ at $280 \mathrm{~nm}$ and 6655 at $287 \mathrm{~nm}$ ), and $\mathrm{H}_{8} \mathrm{bL}^{8}$ (22445 at $281 \mathrm{~nm}$ and 28765 at $290 \mathrm{~nm}$ ). The increase of the $\varepsilon_{s}$, of the complexes suggests that they are stable (1:1 stoichiometry still exists in solution) and formed by cation(PQ) $-\pi$ (calixarene) interaction. The colourless solutions of these complexes indicate that the donor-acceptor interaction more than charge transfer interaction dominates the cation $-\pi$ interaction $[6 \mathrm{~d}, 7 \mathrm{c}]$.

IR spectra of compounds $\mathbf{1}$ and $\mathbf{2}$ showed three small but well-defined bands between 1650 and $1590 \mathrm{~cm}^{-1}$, two of which were located at nearly 1640 and $1560 \mathrm{~cm}^{-1}$ assignable to the stretching frequencies of $-\mathrm{C}=\mathrm{N}-\mathrm{C}-$ of bipyridinium groups of PQ [11a], and the third one centred at $1605 \mathrm{~cm}^{-1}$, corresponding to phenyls of calixarenes [6e]. Changes in symmetry and intensity ratio of the doublet band assignable to tert-butyl groups $\left(1400-1360 \mathrm{~cm}^{-1}\right)$ with respect to that of the free calixarenes were also observed. Below $900 \mathrm{~cm}^{-1}$ the out-of-plane $\mathrm{H}-\mathrm{C}$ aromatic bending vibrations of aryl rings and -HCH- rocking [11b-11c] of the calixarenes underwent significant changes, thus proving that PQ disturbed the hydrophobic calixarene cavity, i.e. the $\pi$-base cavity of the calixarene. The well-defined band about $470 \mathrm{~cm}^{-1}$ assigned to the out-ofplane $\mathrm{H}-\mathrm{C}$ bending vibrations of aromatic rings belonging to the pyridinium groups of PQ was observed with no changes. This pointed to the cation- $\pi$ interactions as the main driving force to the PQ-calixarene association since no significant shift of $-\mathrm{OH}$ vibration frequencies $\left(3310-3110 \mathrm{~cm}^{-1}\right)$ of $\mathrm{H}_{6} \mathrm{bL}^{6}$ or $\mathrm{H}_{8} \mathrm{bL}^{8}$ was observed. This confirmed that there was no hydrogen bonding of their hydroxyls with the $\pi$ density of the pyridinium rings of $\mathrm{PQ}$ and no intramolecular bonding with

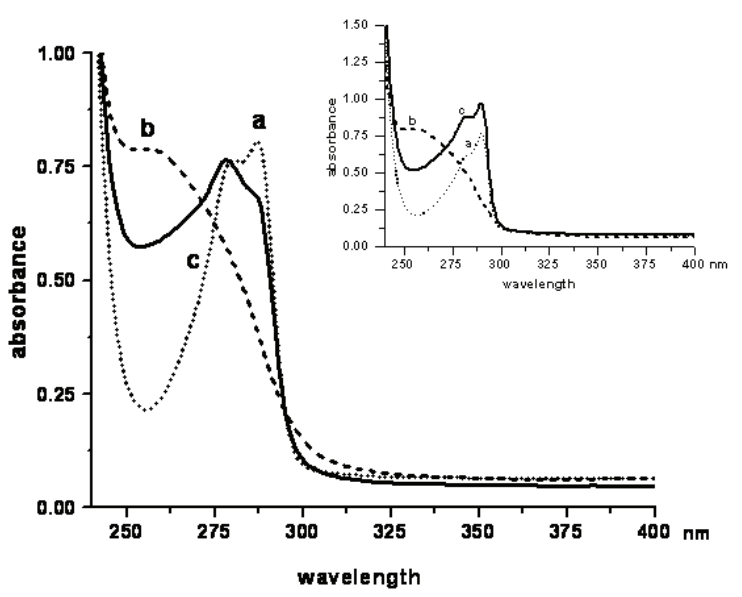

Fig. 1. Fresh solutions of a) $1.13 \times 10^{-4} \mathrm{M} \mathrm{H}_{6} \mathrm{bL}^{6}$, b) $4.7 \times 10^{-5} \mathrm{M}$ paraquat dichloride and c) $2.55 \times 10^{-5} \mathrm{M}$ compound $\mathbf{1}$ in chloroformacetonitrile, v/v: 1:1.2. Inset: the spectra of $\mathrm{H}_{8} \mathrm{bL}^{8} \mathrm{a}$ ), PQ (b), compound 2 (c) solutions. 
the counteranion (chloride), which was expected since PQ is electron-deficient and the ion pair association is strong in the solid state [10b]. It seems then that compounds $\mathbf{1}$ and $\mathbf{2}$ are molecular complexes bonded by associative forces $[6 \mathrm{~b}, 6 \mathrm{e}]$. In addition, the spectrum of compound $\mathbf{1}$ showed an unresolved band at $745 \mathrm{~cm}^{-1}$ assignable to $\mathrm{CHCl}_{3}$ and a very weak broad band centred at $3590 \mathrm{~cm}^{-1}$ assignable to water molecules. The latter is also seen in the spectrum of compound $\mathbf{2}$, both in line with their elemental analyses.

${ }^{1} \mathrm{H}$ NMR spectra of compounds $\mathbf{1}$ and $\mathbf{2}$, the calixarenes and paraquat dichloride, were recorded in their solutions in $\mathrm{CDCl}_{3} / \mathrm{CD}_{3} \mathrm{OD}(2: 1 \mathrm{v} / \mathrm{v})$ mixture in order to find out the extent of the interaction paraquat-calixarene in solution. Figure 2 displays only the region of interest for compound $2, \mathrm{H}_{8} \mathrm{bL}^{8}$ and the paraquat dichloride. The spectrum of the paraquat dichloride (Figure $2 b$ ) shows the signals corresponding to the $\alpha$-bipyridinium protons at $\delta 9.21$ and 9.18 and the $\beta$-bipyridinium protons at $\delta 8.74$ and 8.72. An unresolved quintuplet corresponding to N-Methyl protons is centred at $\delta 4.49$. [9b$9 \mathrm{e}, 10 \mathrm{~d}]$. The $\mathrm{CDCl}_{3} / \mathrm{CD}_{3} \mathrm{OD}$ mixture influenced the conformational behaviour of the calixarenes (Figure 2a) and of the paraquat dichloride calixarene complexes (Figure 2c); therefore, the methylenes are scarcely seen at $\delta 3.8-3.9$ and hydrox$y l$ groups are not seen at all. The two signals corresponding to aryl protons are seen at $\delta 7.46$ and 7.21 and the tert-butyl protons resonate at $\delta 1.27$ and 1.26 . The resonance of the methylene and hydroxyl protons was confirmed in $\mathrm{CD}_{2} \mathrm{Cl}_{2}$. According to the molecular modelling (see below) by MOPAC procedures, in the absence of solvent the molecule acquired a pleated loop-like conformation while in the presence of water a pinched-like conformation was the most stable since the intramolecular hydrogen bonding was disrupted (Figure

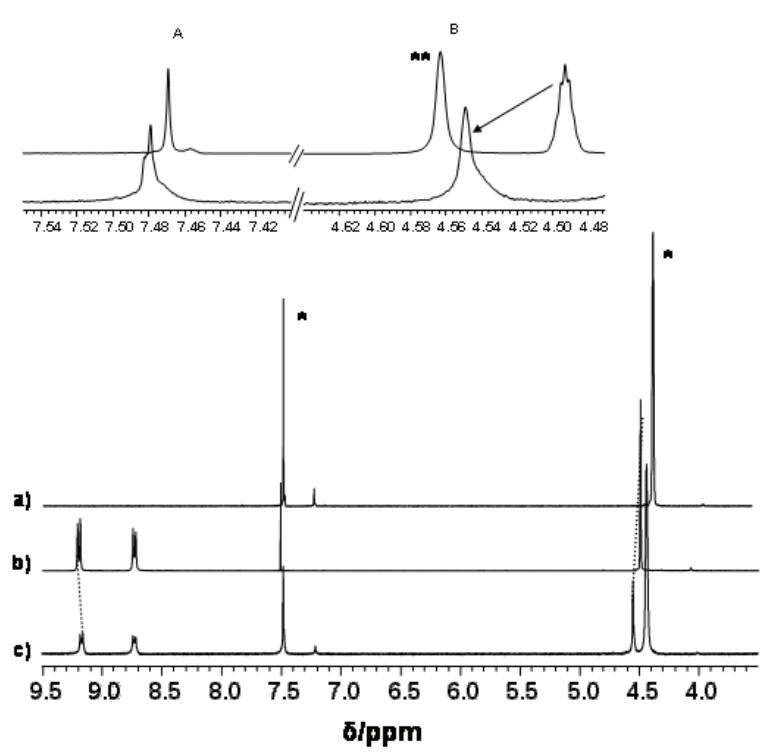

Fig. 2. Partial ${ }^{1} \mathrm{H}-\mathrm{NMR}$ spectra of a) $\mathrm{H}_{8} \mathrm{bL}^{8}$, b) paraquat dichloride, c) compound 2 solutions in 2:1 $\mathrm{CDCl}_{3} / \mathrm{CD}_{3} \mathrm{OD}$. A: Aryl- hydrogen of $\mathrm{H}_{8} \mathrm{bL}^{8}$ (top), compound 2 (bottom). B: Methyl proton of pyridinium of paraquat (top), compound 2 (bottom). * solvent residual peaks. **residual water and water from the sample.
5). However, if the solvent polarity is not strong enough to disrupt the intramolecular hydrogen bonding of para-tertbutylcalix[8]arene, completely, the pinched or pleated loop conformations are probable $[6,12]$.

The spectrum of compound 2 (Figure 2c) shows little change with respect to that of the free calixarene and paraquat. The $N$-methyl protons appear downfield as an asymmetric singlet centred at $4.55 \mathrm{ppm}$. This slight change with respect to that of the free paraquat resonance suggests that the two $\mathrm{N}$ methyl protons are in a similar environment and that the downfield shift $(+\Delta \delta=0.06 \mathrm{ppm})$ is due to the interaction of paraquat with the calixarene, which is expected for this substrate when residing in the deshielding environment of the calixarene receptor, i.e. close to its hydroxyl phenolic groups. Curiously, the most stable structure found by molecular modelling was that resulting from the cation- $\pi$ interactions positioned in the double bond located between the meta-Carbon and $\mathrm{OH}-$ carbon of the phenolic groups, Fig. 5. The $\alpha$-pyridinium protons are moved slightly upfield $(-\Delta \delta=0.03 \mathrm{ppm})$, probably due to the weak effect of the shielding region of the aryl rings of the calixarenes. Since the methylenes and hydroxyl protons are not adequately seen because of the conformational mobility of the calixarene using the solvent mixture, only a partial integration of the signals is possible for compound $\mathbf{2}$. Thus, the relation of the ratio of pyridinium protons/methyl $-\mathrm{N}$ protons to the ratio of tert-butyl protons/ phenyl protons from the spectrum is similar to that calculated for 1:1 stoichiometry and found by EA in the solid state. Similar resonance behaviour is found for compound 1 under the same experimental conditions. ${ }^{1} \mathrm{H}$ NMR spectra of these compounds do not afford enough evidence of their stabilities in solution. It has been reported that de-tert-butylated hexametoxi calix[6,8]arenes interact strongly with $N$-methyl pyridinium (one Quat) by cation- $\pi$ interaction $(-0.250,-0.189 \mathrm{ppm})[7 \mathrm{c}]$, while this is weak with para-tertbutylcalix[5]arene [7b]. At first glance, this implies an adverse effect of tert-butyl groups mobility in the Quats-calixarene compounds in solution. In compound $\mathbf{2}$, the pinched conformation of the calixarene is maintained in agreement with the literature [12].

The ESI-MS spectra of compounds 1 (1PQ:1para-tertbutylcalix[6]arene $\cdot \mathrm{H}_{2} \mathrm{O} \cdot \mathrm{CHCl}_{3}$ ) and 2 (1PQ:1 para-tertbutylcalix [8] arene $\cdot \mathrm{H}_{2} \mathrm{O}$ ) were obtained in $\mathrm{CHCl}_{3} / \mathrm{CH}_{3} \mathrm{OH}$ mixture $(1: 2(\mathrm{v}) \mathrm{v})$. Although the ionisation pattern of both complexes is similar, it reveals that $\mathbf{1}$ is much more ionisable than 2 . The most relevant peaks which suggest that in solution both paraquat calixarene compounds seem to exist in 1:1 stoichiometry are at $m / z,[\mathbf{1}-\mathrm{Cl}-5 \mathrm{H}], 1327.1 ;\left[\mathbf{1}-2 \mathrm{Cl}-\mathrm{H}_{2} \mathrm{O}-\mathrm{CHCl}_{3}\right.$ $+\mathrm{K}]^{3+}, 599.5$; $\left[\mathbf{1}-2 \mathrm{Cl}-3 \mathrm{H}_{2} \mathrm{O}-\mathrm{CHCl}_{3}-\mathrm{OH}+\mathrm{H}^{3+}, 368.4\right.$ for $\mathbf{1}$, and at, $m / z,[2-2 \mathrm{Cl}-6 \mathrm{H}], 1496.2 ;\left[2-\mathrm{H}_{2} \mathrm{O}+2 \mathrm{CH}_{3} \mathrm{OH}+2 \mathrm{H}\right]^{2+}$ 810.9; $\left[2-2 \mathrm{Cl}+\mathrm{CH}_{3} \mathrm{OH}\right]^{2+}, 757.9 ;[2-2 \mathrm{Cl}+\mathrm{K}]^{3+}, 513.7$ for 2. In both cases the loss of hydrogens is due to the hydrolysis of the HO-phenolic rings of the calixarenes [6a,e] in organic solvents. A similar fragmentation pattern has been observed in several pseudorotaxanes and catenanes derived from paraquat derivatives, paraquat halides and paraquat hexafluorophosphate $[9 \mathrm{e}, \mathrm{f}]$. 
The luminescent properties of compounds $\mathbf{1}$ and $\mathbf{2}$ and those of the free calixarenes and PQ were studied in the solid state (powder) and solutions at $293 \mathrm{~K}$ and $77 \mathrm{~K}$. Their lifetimes were recorded at $77 \mathrm{~K}$. The aim of the study in solution was to look for further evidence of the stability and stoichiometry of the molecular complexes.
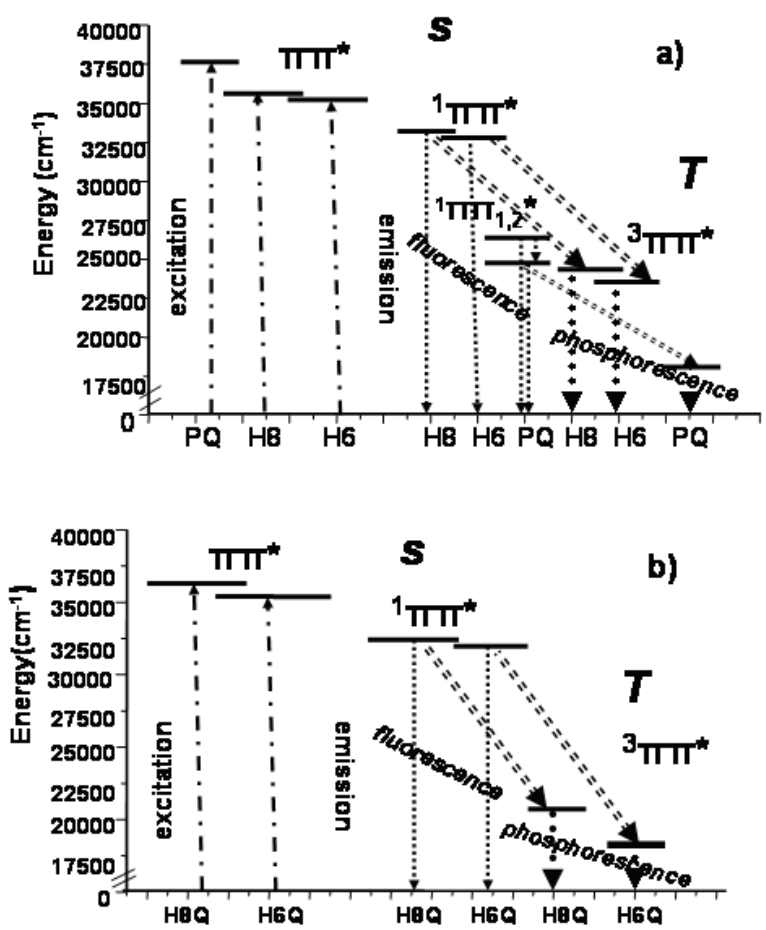

Fig. 3. Energy Diagram built from the luminescence spectra recorded in powder at $77 \mathrm{~K}$ of a) calixarenes and paraquat and b) their isolated molecular complexes.

In the solid state at $293 \mathrm{~K}$, the emission fluorescence spectra of PQ, calixarenes and molecular complexes showed extra bands due to vibronic contributions from the lattice $(\mathrm{OH}$ from water molecules, $\mathrm{CH}$ of chloroform (compound 1). At $77 \mathrm{~K}$, excitation and emission phosphorescence spectra of the calixarenes and PQ were less structured than at $293 \mathrm{~K}$, as expected, since the vibronic contributions were frozen. The excitation spectra of the molecular complexes looked structured, and the bands were less intense and slightly shifted (1 to $7 \mathrm{~nm})$ to lower energy with respect to those of the calixarenes and PQ. This was further evidence of the PQ-calixarene association.

The diagram of energy of the calixarenes, PQ and the molecular complexes were built using the parameters of the excitation and emission spectra recorded in the phosphorescence mode at $77 \mathrm{~K}$, in powder samples, (Figure 3). According to these diagrams, if the receptors and the substrate had not been bonded, a poor energy transfer from the calixarenes to PQ would have occurred because the energy gap $\Delta \mathrm{E}={ }^{3} \pi \pi^{*}{ }_{\mathrm{R}}$ $-{ }^{1} \pi \pi^{*}$ s was around $2000 \mathrm{~cm}^{-1}$. However, the formation of the molecular complexes yielded a diagram of energy with a new distribution of the energy levels pointing to ${ }^{1} \pi \pi^{*} \rightarrow{ }^{3} \pi \pi^{*}$ energy transfer from the calixarenes to $\mathrm{PQ}$, with energy gap
$\left(\Delta \mathrm{E}_{\mathrm{RS}}={ }^{1} \pi \pi_{\mathrm{R}}{ }_{-}{ }^{3} \pi \pi_{\mathrm{S}}{ }^{*}\right)$ equal to $8601 \mathrm{~cm}^{-1}$ and $8673 \mathrm{~cm}^{-1}$ for compounds $\mathbf{2}$ and $\mathbf{1}$, respectively. Since the triplet state from the $\pi$ bonds of these compounds must be the emitter level in the molecular complexes, the magnitude of the energy transfer is related to significant cation- $\pi$ interactions.

In Figure 4, the phosphorescence emission spectra of PQ, $\mathrm{H}_{8} \mathrm{bL}^{8}$ and compound $\mathbf{2}$ are given. In the emission spectrum of $\mathrm{PQ}$, (Figure 4A,a) which is weak and complex, two main broad bands are seen, one centred at $421 \mathrm{~nm}$ corresponding to the ${ }^{1} \pi \pi^{*}$ transition state emission and the other centred at $539 \mathrm{~nm}$, which is indicative of emission from its ${ }^{3} \pi \pi^{*}$ transition state. The emission spectrum of $\mathrm{H}_{8} \mathrm{bL}^{8}$ (Fig. 4A,c) reveals a partial energy transfer from its ${ }^{1} \pi \pi^{*}$ transition state (at 308 $\mathrm{nm}$ ) to its ${ }^{3} \pi \pi^{*}$ transition state (centred at $423 \mathrm{~nm}$ ) since a complete transfer would imply the absence of the former, at least at $77 \mathrm{~K}$.

The feature of the spectrum of $\mathbf{2}$ (Figure 4A,b) is different from that of the free substrate and receptor, revealing the emission from the ${ }^{1} \pi \pi^{*}$ transition state of $\mathrm{H}_{8} \mathrm{bL}^{8}$, but the intensity decreases $50 \%$ and the band is $1 \mathrm{~nm}$ red shifted. From this state the energy is transferred to a transition state whose position and shape belong neither to that of the receptor nor to
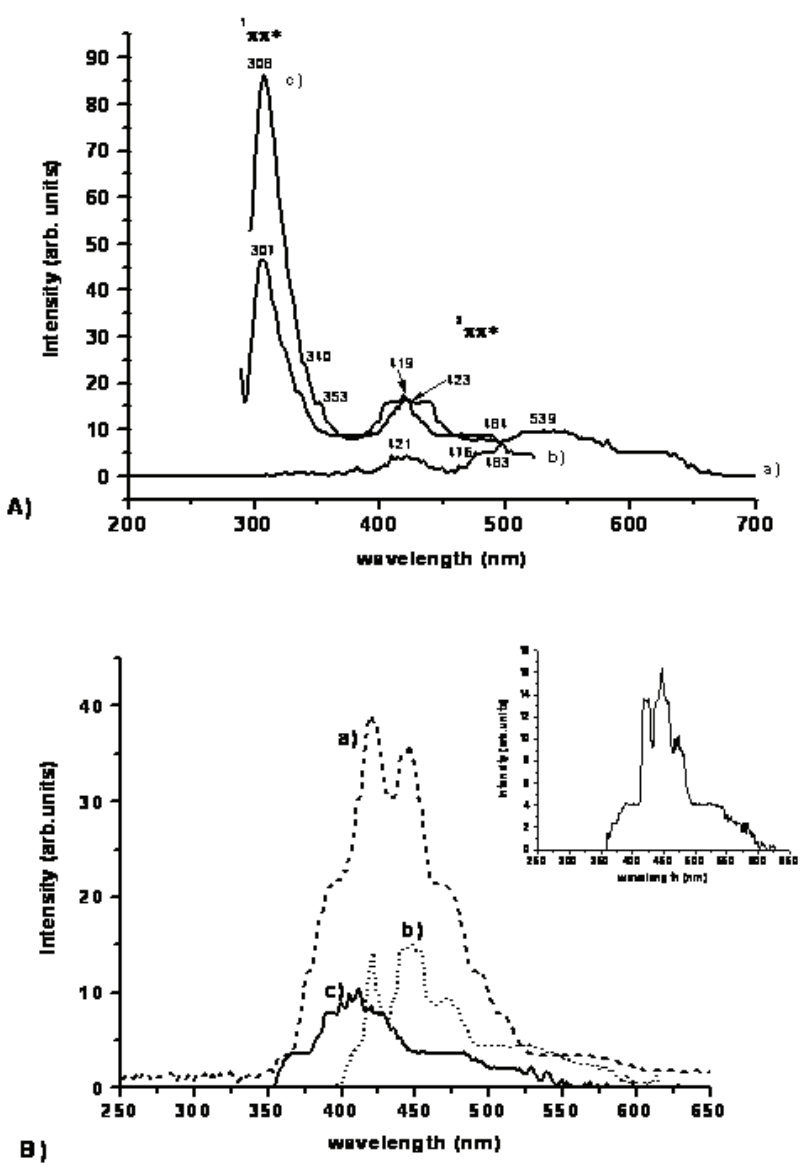

Fig. 4. A) Emission spectra in phosphorescence mode in powder at $77 \mathrm{~K}$ of a) paraquat dichloride, $\lambda_{\text {exc }}=265 \mathrm{~nm}$, b) compound $2, \lambda_{\text {exc }}=$ $275 \mathrm{~nm}, \mathrm{c}) \mathrm{H}_{8} \mathrm{bL}^{8}, \lambda_{\mathrm{exc}}=279 \mathrm{~nm}$. B) In the frozen solution of a) compound $2, \lambda_{\text {exc }}=281 \mathrm{~nm}, \mathrm{~b}$ ) paraquat dichloride $\lambda_{\mathrm{exc}}=261 \mathrm{~nm}$, and c) $\mathrm{H}_{8} \mathrm{bL}^{8}, \lambda_{\text {exc }}=281 \mathrm{~nm}$. 
the substrate, (Figure 4Aa,c). This is a well-defined band at $419 \mathrm{~nm}$ assigned to a ${ }^{3} \pi \pi^{*}$ transition state which de-excited through a ${ }^{3} \pi \pi^{*}$ transition state (about $500 \mathrm{~nm}$ ) to the ground state. The evidence points to the energy transfer from $\mathrm{H}_{8} \mathrm{bL}^{8}$ to $\mathrm{PQ}$, proving once more the $\mathrm{PQ}$-calixarene association by cation- $\pi$ interaction. The energy transfer is not complete since the emission of both compounds is quenched by the presence of water in 2, and even more by chloroform and water in $\mathbf{1}$. Therefore, the emission spectrum of the latter is very weak.

The luminescence lifetime $(\tau)$ is a parameter frequently correlated with the structure and stability of an emitting species [13]. The lifetimes of $\mathrm{PQ}, \mathrm{H}_{8} \mathrm{bL}^{8}, \mathrm{H}_{6} \mathrm{bL}$ and their molecular complexes, compiled in Table 1, are interpreted as follows: two lifetimes for each molecular complex indicated a biexponential decay pointing to two pathways for de-excitation from the triplet state to the ground state, while one $\tau$ for the calixarenes and PQ evidenced a mono-exponential decay. As has been established, in $\mathrm{PQH}_{6} \mathrm{bL}^{6}$ and $\mathrm{PQH}_{8} \mathrm{bL}^{8}$ molecules, the QUAT1 $-\pi$ bond length is different from that of QUAT2- $\pi$, that of $\mathrm{PQH}_{8} \mathrm{bL}^{8}$ being the shorter of the two. This is related to the size and the particular conformations acquired by each calixarene and to the better shielding of one Quat site over the other. Therefore, if the two bonding sites have different surroundings, the de-excitation must be through two pathways, at least.

The two lifetimes of $\mathbf{2}$ are longer than those of $\mathbf{1}$. This demonstrates that in the latter, the presence of $\mathrm{CHCl}_{3}$ apart from $\mathrm{H}_{2} \mathrm{O}$, contributes to a faster de-excitation. Moreover, it is evident that both compounds have the same type of de-excitation pathways through the QUAT- $\pi$ (calixarene) moieties because the $\tau_{\mathrm{R} \text { (receptor) }} / \tau_{\mathrm{RS} \text { (complex) }}$ ratio of their longer lifetimes is similar, 4.2 and 3.9, for compounds $\mathbf{2}$ and $\mathbf{1}$, respectively. The shorter lifetime indicates the de-excitation through the bonding site less shielded from the lattice (Table 1). This is revealed also in the $\tau_{R} / \tau_{R S}$ ratio of the shorter lifetimes 5.1 for $\mathbf{2}$ and 12 for $\mathbf{1}$. The geometrical parameters and the arrangement of the structure of $\mathbf{1}$ (Figure 5a, Table 2) from the molecular modelling suggest that one pyridinium cation (QUAT1 or QUAT2) is exposed to the medium which explains the significant difference between the lifetimes of $\mathbf{1}$. The difference between the lifetimes of $\mathbf{2}$ is also explained in terms of its modelled structural arrangement (Figure 5b). Therefore, it is proposed that the effect of paraquat in the $\pi$ - base cavity of the calixarenes is tuned by the size of PQ and the size and conformational properties of the calixarenes, which definitely affect the strength of their cation- $\pi$ interactions.

The stability of the complexes in solution was investigated by a luminescence study in a chloroform /acetonitrile mixture $(\mathrm{v} / \mathrm{v}, 1: 1.2)$ at $293 \mathrm{~K}$ and in frozen solutions at $77 \mathrm{~K}$.

At $293 \mathrm{~K}$, the band width decreases about $100 \mathrm{~nm}$ with respect to the spectrum in the solid state, is asymmetric and centred at about $353 \mathrm{~nm}$ with a shoulder at about $307 \mathrm{~nm}$. In compound 2 , the band intensity decreased $60 \%$ with respect to that of the free PQ and $57 \%$ with respect to the calixarene. This demonstrates that in solution the 1:1 stoichiometry of $\mathbf{2}$ is kept at approx. $1 \times 10^{-4} \mathrm{M}$ concentration. The spectrum of 1, decreased only with respect to the substrate (20\%). At first glance, this indicates an incomplete inclusion of PQ in the calixarene or partial de-complexation.

To confirm those findings at $293 \mathrm{~K}$, the solutions were frozen $(77 \mathrm{~K})$, and their phosphorescence spectra as well as lifetimes were recorded. Here, only the bands corresponding to the ${ }^{3} \pi \pi^{*}$ transition state of the substrate and of the receptors were seen; in $\mathbf{1}$ and $\mathbf{2}$, it is the ${ }^{3} \pi \pi^{*}$ transition state which receives the energy from the singlet and/ or triplet transition states of the calixarenes and which is expected to be close to that of PQ. From such a level the light is re-emitted; then the intensity of the emission spectra must rise. This is the case for compound 2. Its spectrum is given in Figure 4B,a, which, compared with that of the substrate and the receptor as well as with the spectrum in powder at $77 \mathrm{~K}$, given in Figure 4A, reveals that the solvent and lattice effects are eliminated and the larger intensity indicates that the 1:1 stoichiometry of the compound is preserved. The luminescence behaviour of $\mathbf{1}$ in the frozen solution confirms the fact that such an energy transfer is poor (inset, Figure 4B), but the feature of the spectrum together with the luminescence intensity, which is slightly larger than that of the substrate, points not to a decomplexation of the compound but to an incomplete protection of PQ by the calixarene cavity, as suggested by the experimental and theoretical results already discussed. The decisive proof was the lifetime measured in frozen solutions, Table 1. Three important

Table 1. Phosphorescence ( ${ }^{3} \pi \pi^{*}$ transition state) lifetimes of the free receptors, substrate and molecular complexes in powder and in chloroformacetonitrile frozen solutions at $77 \mathrm{~K}$

\begin{tabular}{|c|c|c|c|c|c|c|}
\hline Compounds & \multicolumn{6}{|c|}{ Parameters } \\
\hline PQ & 265 & 538 & 868 & 261 & 448 & 685 \\
\hline $\mathrm{H}_{6} \mathrm{bL}^{6}$ & 289 & 429 & 658 & & No measured & No measured \\
\hline $\mathrm{H}_{8} \mathrm{bL}^{8}$ & 279 & 423 & 970 & 281 & 420 & 777 \\
\hline$\left[\mathrm{PQH}_{8} \mathrm{bL}^{8}\right] \cdot \mathrm{H}_{2} \mathrm{O}$ & 275 & 481 & $(190,229)$ & 261,281 & 420 & $(246,287)$ \\
\hline
\end{tabular}


aspects of compounds $\mathbf{1}$ and $\mathbf{2}$ can be seen. The first is that the luminescence decay is kept bi-exponential as in the solid state, which indicates non-decomplexation in any case; otherwise, the lifetimes would be similar to those found for the free calixarenes and PQ. Secondly, the shortest lifetime of $\mathbf{1}$ increases substantially, 3.5 times with respect to the solid state, and the longest lifetime increases moderately; in the case of $\mathbf{2}$ both lifetimes increase slightly and similarly ( 1.3 times). Once more it is demonstrated that in $\mathbf{1}$ one Quat is much more exposed to the lattice than the other and that the solvent destroys the lattice effect without affecting the stability of the complex. In $\mathbf{2}$, the entire PQ is definitely shielded by the calixarene cavities, resulting in $\mathbf{2}$ being more stable than $\mathbf{1}$. Thus, the luminescence studies in solution at 293 and $77 \mathrm{~K}$ confirm stronger QUAT $-\pi$ interactions in $\mathbf{2}$ than in $\mathbf{1}$. The extent of their stability is highly influenced by the conformations and sizes of the substrate and the receptors. We conclude that the 1:1 stoichiometry of $\mathbf{1}$ and $\mathbf{2}$ in the solid state is kept in solutions of aprotic solvents even at a lower concentration than $1 \times 10^{-4} \mathrm{M}$. However, in polar/protic solvents, H'NMR and ESI-MS did not allow us to confirm such stability.

\section{Molecular modelling}

Semiempirical computational procedures are useful tools in supramolecular chemistry $[7,14]$ which can be used to discern the conformational behaviour of large organic molecules and to explore the possibilities of molecular recognition between neutral or charged molecules [6b, 6e, 7a-e, 8]. The calixareneparaquat interaction lies in this field. Usually, computational calculations of complex molecules formed between Quats and organic receptors similar to calixarenes, (i.e., naphthalenophanes) do not take into account the counteranions of the Quats (substrate) or solvent effects [8b]. The counteranion and solvent effects on the complexation of Quats by neutral calixarene receptors $[7 \mathrm{a}, 6 \mathrm{~b}, 7 \mathrm{c}, 10 \mathrm{c}]$, either parent calixarenes [6b-c] or functionalized calixarenes, $[7 \mathrm{a}, 7 \mathrm{~b}]$ including sophisticated ones such as calixarene wheels, have been demonstrated [10c]. The main driving force, the cation- $\pi$ interactions, behind the formation of Quat-calixarene complexes is influenced by the counteranions while the solvent polarity affects the complexation. In this study, the molecular modelling including or excluding the effect of these parameters was necessary in order to explore the possibilities of molecular recognition between the parent calixarenes and the paraquat dichloride to find adequate theoretical evidence for a suitable experimental design for synthesising the complexes and to discern the conformational behaviour of the paraquat, calixarenes and the molecular complexes as well as to obtain some calculated structural parameters.

X-ray diffraction structures of some Quat-calixarene complexes have shown that the cation interacts with the $\pi$-electron density of the calixarene rings $[8,10]$. By molecular modelling, the best approach was by anchoring the two pyridinium cations of PQ to the double bonds of two specific phenyl groups of each calixarene, thus forming localised cation- $\pi$ interactions
(Figure 5). The stablest complex structure resulted from the cation- $\pi$ interactions occurring with the double bonds located between the carbon holding the hydroxyl groups and the carbon bonded to the methylene groups of the calixarene. Table 2 shows the energies of the most stable molecules.

The heat of formation of $\mathrm{PQH}_{6} \mathrm{bL}^{6}$ and $\mathrm{PQH}_{8} \mathrm{bL}^{8}$ molecules was more negative in the presence of water (Table 2, fourth column, $\mathrm{H}^{*}$ ), thus indicating that solvation with a polar solvent such as water could break the intramolecular bonding of the calixarenes formed in the absence of the solvent, favouring the interaction of the two bipyridinium units with the calixarene cavity. The cation-chloride distances for the free paraquat dichloride in the absence of water was $<3 \AA$ while $>4 \AA$ in its presence. This behaviour was in agreement with experimental results which demonstrate that the weakening or disruption of the ion pair association in quats occurs with polar solvents $[7 \mathrm{a}, \mathrm{b}]$. However, in the case of the molecular complex in water, the ion pair association is strengthened since the cation-chloride bond distance was $<<3 \AA$, in particular for $\mathrm{PQH}_{6} \mathrm{bL}^{6}<2 \AA$. According to these calculations the inclusion of paraquat dichloride in the calixarenes studied would be driven by the size and conformation of the receptors as well as by the size of the substrate PQ, Figure 5. It has been reported that the binding of quats to neutral receptors in low polar solvents is strongly influenced by the counterion nature $[7 \mathrm{a}, \mathrm{b}]$ in particular when the counteranion is spherical. It has been reported that para-tert-butyl substituents at the upper rim of the calixarene exert steric interference with substrate inclusion, thus affecting the stability of the inclusion complexes[7b,c].

$\mathrm{PQH}_{6} \mathrm{bL}^{6}$ association, Fig. 5a, (Table 2) revealed longer cation- $\pi$ interaction bond lengths than those of $\mathrm{PQH}_{8} \mathrm{bL}^{8}$ (Figure $5 \mathrm{~b}$ ). The dihedral angles (Column 6) pointed to a more
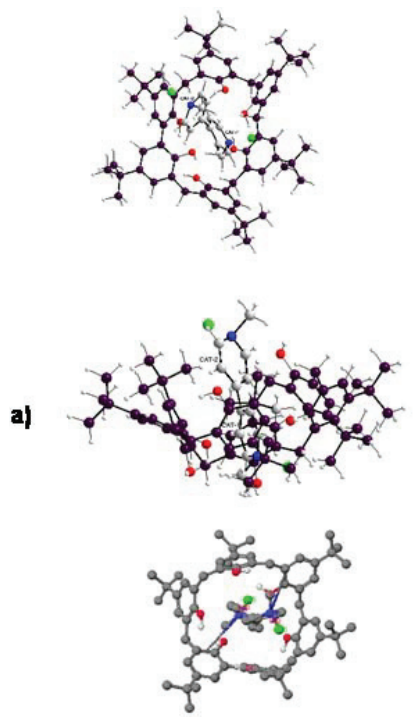
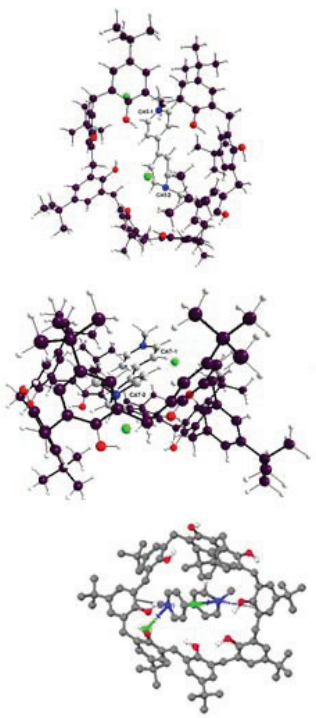

Fig. 5. Refined structures of Paraquat Dichloride-calixarene molecules from MOPAC/PM5/COSMO calculations a) top left, $\mathrm{PQH}_{6} \mathrm{bL}^{6}$, b) top right, $\mathrm{PQH}_{8} \mathrm{bL}^{8}$ both enhanced by Diamond software. In the middle, another view of the complex molecules. At the bottom, other view of the structures showing the Cation- $\pi$ interactions. Hydrogens bound to carbons are not shown for simplicity. 
distorted molecular complex for $\mathrm{PQH}_{6} \mathrm{bL}^{6}$ than for $\mathrm{PQH}_{8} \mathrm{bL}^{8}$. The bond angles, dihedral angles and improper torsion angles (Columns 5 and 6 ) between the two pyridinium units and the phenyl rings provide evidence that the paraquat is not planar in the complexes. For instance, the angles between 164 and $169^{\circ}$ were found under the solvent effects of water. In the absence of water and/or completely ionised paraquat, the planarity of PQ in the complexes was little disturbed since angles between $172-180^{\circ}$ were found.

In the absence of water, hydrogen bonding between a hydrogen of one pyridinium cation with its chloride occurred in $\mathrm{PQH}_{8} \mathrm{bL}^{8}$ while in $\mathrm{PQH}_{6} \mathrm{bL}^{6}$, hydrogen bonding between a chloride and a hydroxyl of the calixarene is formed. In any case, chloride ions would affect the degree of stability of the species. The latter has been already proven experimentally $[7 \mathrm{a}$, $6 \mathrm{~b}, 10 \mathrm{c}]$.

The calculated structural parameters, together with the potential energies and the heat of formation, demonstrated that $\mathrm{H}_{8} \mathrm{bL}^{8}$ has sufficient cavity size to include PQ, Fig. $5 \mathrm{~b}$. Consequently, relatively strong cation- $\pi$ interactions were expected in $\mathrm{PQH}_{8} \mathrm{bL}^{8}$. In contrast, in the case of $\mathrm{PQH}_{6} \mathrm{bL}^{6}$ (Figure 5a) the paraquat was not well included in the calixarene. Therefore, it must have been more exposed to the medium. In addition, the $\mathrm{N}-\mathrm{Cl}$ distance in $\mathrm{PQH}_{8} \mathrm{bL}^{8}$ is $>2.6 \AA$ while in $\mathrm{PQH}_{6} \mathrm{bL}$ is $<1.8 \AA$, which implies a competition between the cation and anion for the binding sites in the calixarene and then an adverse effect in the strength of the cation- $\pi$ interactions. These aspects favour a major exposition to the medium in $\mathrm{PQH}_{6} \mathrm{bL}^{6}$ than $\mathrm{PQH}_{8} \mathrm{bL}^{8}$.

From a qualitative point of view, the positive sign of the estimated heat of reaction $(H)$, (Table 2, fourth column) calculated from the heat of formation under the solvent effects of water suggested that the formation of the paraquat dichloride calixarene complexes, even in the polar solvent, would be governed by an endothermic reaction which would mean that a calorific energy would have to be supplied to the experimental reaction medium. The PQ-calixarene complexation should be entropically disfavoured with the loss of calixarene mobility. However, the calculated potential energy (at $0 \mathrm{~K}$, entropy is cero) is high with respect to those of free PQ and calixarenes. Therefore, up to the stage of our semiempirical calculations, we can propose only that any reaction between the substrate and the receptor would require heating in order to obtain the PQ complexes in low polar solvents.

\section{Testing the stability in water of the PQ calixarene complexes}

The aim of this preliminary study was to discover any usefulness of the parent calixarenes for the herbicide paraquat in an aqueous medium. Samples of the isolated molecular complexes were treated with water in order to investigate the extent of the stability of $\mathrm{PQH}_{6} \mathrm{bL}^{6}$ and $\mathrm{PQH}_{8} \mathrm{bL}^{8}$ in tap water $(\mathrm{TW}, \mathrm{pH}=7.72)$ and distilled water $(\mathrm{DW}, \mathrm{pH}=5.44)$ ) at their own $\mathrm{pH}$. The IR spectrum of the dried fraction from compd. 1 after being treated with TW demonstrated that the remaining PQ was still linked to the calixarene since a shoulder at $1635 \mathrm{~cm}^{-1}$ corresponding to the bipyridinium cation of $\mathrm{PQ}$ was seen on the left side of the aromatic calixarene band (at $1610 \mathrm{~cm}^{-1}$ ). The spectrum of the dried sample from DW treatment revealed structured weak bands at 1560, 1508, 1442 $\mathrm{cm}^{-1}$ and at $1639 \mathrm{~cm}^{-1}$ also associated with PQ [11a]. In both cases, spectra showed a broad band centred at about 3431 $\mathrm{cm}^{-1}$, indicative of imbibed water and at about $3140 \mathrm{~cm}^{-1}$ for HO-calixarene vibration, the latter shifted $14 \mathrm{~cm}^{-1}$ towards higher energy with respect to that of the molecular complex and free calixarene (discussed above). The calculations from UV-visible spectra data of the corresponding transparent aque-

Table 2. Calculated energies of the modelled molecules using computational procedures. The energies are given in $\mathrm{kcal}^{\mathrm{mol}}{ }^{-1}$.

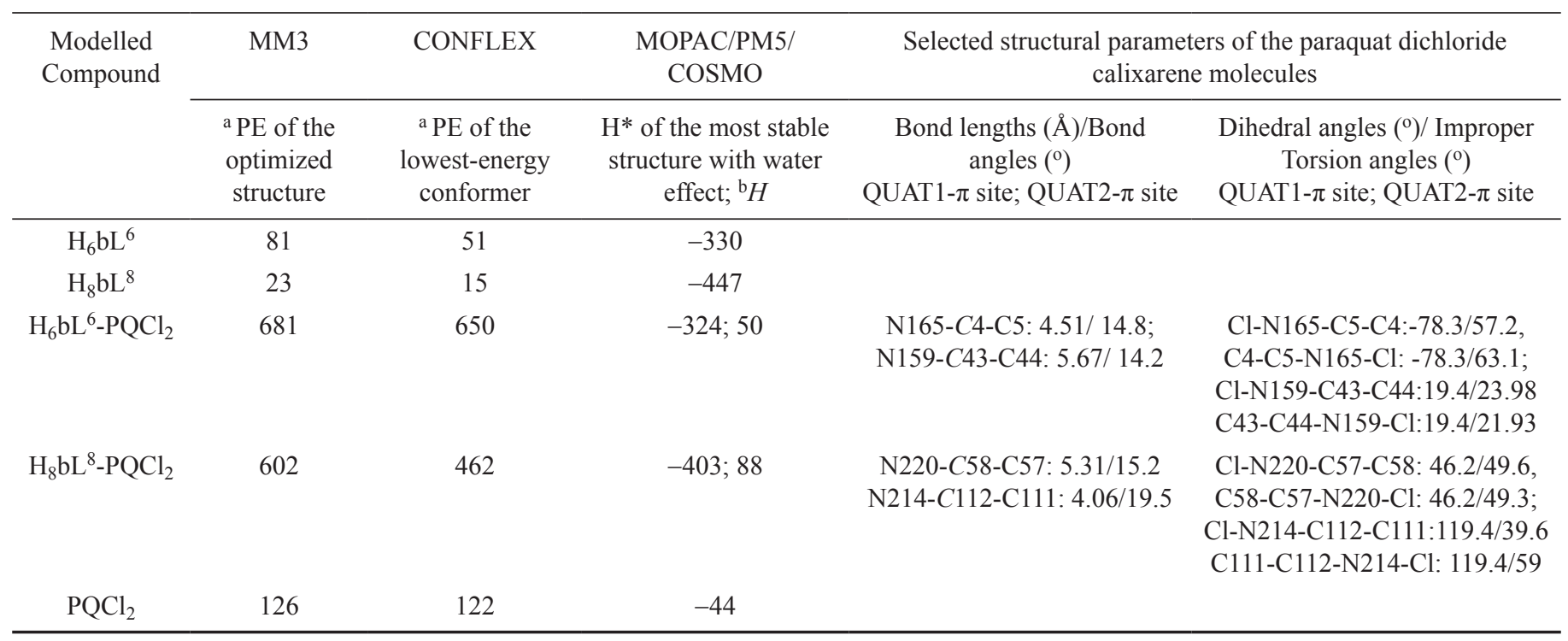

${ }^{\text {a } P E: ~ P o t e n t i a l ~ E n e r g y ; ~}{ }^{\mathrm{b}} H$ : estimated heat of reaction. 
ous fractions and the PQ content of the molecular complex indicated that TW removed about $63 \%$ of $\mathrm{PQ}$, being retained $37 \%$ by $\mathrm{H}_{6} \mathrm{bL}^{6}$ while DW treatment left only $8 \%$ of $\mathrm{PQ}$ in the calixarene. It was discussed above the low stability of compd. 1 in polar and protic solvents, therefore it was expected that the stability would be much lower in water as it was but it was also $\mathrm{pH}$ dependent; $\mathrm{pH}<6$ provoked $\mathrm{PQ}-\mathrm{H}_{6} \mathrm{bL}^{6}$ de-association while $\mathrm{pH}>6$ had a less drastic effect. The transparency of both water fractions indicated no presence of the molecular complex in it, and their UV-visible bands were indicative of PQ only. It was assumed that in the slightly acidic medium, the cation-calixarene interactions were broken by protonation whereas at a slightly basic $\mathrm{pH}$, less $\mathrm{H}^{+}$concentration would not destroy drastically such interactions and then part of the molecular complex would survive. Paraquat is ionised in water then in Compd. 1 its exposure to the medium though partially contributed to increase the acidity of water due to chloride ions, which were liberated by the PQ ionisation.

The IR spectrum of the dried fraction from compound 2 after the treatment with DW showed a red shift of the $\mathrm{OH}-$ calixarene vibration band $\left(12 \mathrm{~cm}^{-1}\right)$ with respect to the free calixarene and the untreated compound; weak bands indicative of PQ were also noticed, and changes in the intensities of bands associated with tert-butyl and methylene groups, and $\mathrm{CH}$ of out-of -the plane of the aromatic rings were seen. In the IR spectrum of the dried sample treated with TW was observed: a slightly broad band in the $\mathrm{OH}$ vibration regions, a semi-broad band centred at $1116 \mathrm{~cm}^{-1}$ assigned to C-O stretching vibration of the HO-C- phenol groups of the calixarene and a strong band centred at $538 \mathrm{~cm}^{-1}$, indicative of bending vibration of $\mathrm{CH}$ of aromatic rings apparently from $\mathrm{PQ}$. Water imbibed in $\mathrm{H}_{8} \mathrm{bL}^{8}$ calixarene was not revealed. Aqueous fractions from both treated samples of the molecular complex looked emulsified and in their UV-visible spectra, bands about 248 and $273 \mathrm{~nm}$ and 256-259 $\mathrm{nm}$ indicated the presence of $\mathrm{H}_{8} \mathrm{bL}^{8}$ and PQ. $\mathrm{H}_{8} \mathrm{bL}^{8}$ retained about $48 \%$ of PQ independent of the water source and $\mathrm{pH}$, since the emulsified aqueous fractions contained about $52 \%$ of $\mathbf{2}$. The emulsification indicated that $\mathrm{PQ}$ remained linked to $\mathrm{H}_{8} \mathrm{bL}^{8}$ in water. The latter was proven when the separation of $\mathrm{PQ}$ from aqueous phases was attempted at $\mathrm{pH}: 3.0,5.5$ and 7.97 with $\mathrm{H}_{8} \mathrm{bL}^{8}$ in saturated chloroform; both organic and aqueous phases were transparent, and even in the presence of acetonitrile as a synergic agent, no extraction of PQ to the organic phase or $\mathrm{H}_{8} \mathrm{bL}^{8}$ to the aqueous phase was revealed. Therefore, it can be established that the stability of $\mathrm{PQH}_{8} \mathrm{bL}^{8}$ complex does not depend on $\mathrm{pH}$; one part of the sample remained in the aqueous fraction and the other in the solid fraction in both fractions as a stable molecular complex. The emulsification of $\mathbf{2}$ in water seems to be caused by hydrogen bonding between water molecules and the hydroxyl groups of the calixarene, such a bonding being favoured apparently by the particular pinched cone-like conformation of the calixarene in the molecular complex (Figure $5 b$ ), where the hydroxyls are exposed to the medium while the substrate is hidden by an endo-like structural arrangement. In the case of $\mathbf{1}$, its low stability in water could result from the highly distorted in-out cone conformation (see Figure 5a) acquired by the calixarene, which leaves the ionised bonded substrate in an exo structural arrangement thus without any or with little shielding from the medium.

\section{Conclusions}

Para-tert-butylcalix[6]arene and para-tert-butylcalix[8]arene calixarenes form stable 1:1 complexes with paraquat dichloride in the solid state. In solution, the stability of these complexes could be affected by the solvent polarity and the conformation and size of the macrocycle, mainly. However, the increase of the molar absorption coefficient and of the luminescence intensity of the complexes with respect to that of the calixarene receptors evidence cation $-\pi$ interactions. The biexponential decay of the luminescence and the extent of the lifetimes proved that in both complexes the quats of the paraquat were not in the same environment. This fact was correlated with the molecular modelling since two de-excitation pathways were present with very different lifetimes, the longer associated with one methyl-pyridinium head closer to the aryl rings and the shorter with the methyl-pyridinium head far from the aryl rings, the former being more shielded than the latter.

The molecular modelling was also useful in assessing structural parameters since the attempts to obtain crystals for $\mathrm{X}$-ray diffraction structures failed. The preliminary test in water suggests that the stability of PQ-pt-butylcalix[8]arene complex does not depend on the $\mathrm{pH}$ while that of PQ-ptbutylcalix[6]arene does, and in any case the former is much stabler than the latter in an aqueous medium. Then it can be envisaged that $p t$-butylcalix [8]arene would be useful if it were required to stabilise the paraquat dichloride in solid, organic and water solutions for its deposition/de-activation as waste.

To the best of our knowledge, this is the first time that paraquat calixarene molecular complexes formed with parent calixarenes and the herbicide paraquat dichloride have been synthesised, isolated and studied in solid and solution states.

\section{Experimental Section}

\section{Materials}

Paraquat dichloride, (1,1'-Dimethyl-4,4'-bipyridinium dichloride) was bought from Fluka, Germany; 5, 11, 17, 23, 29, 35-hexabutyl 37, 38, 39, 40, 41, 42-hexahydroxicalix[6]aren $\mathrm{e}$, para-tert-butylcalix[6]arene, $\left(\mathrm{H}_{6} \mathrm{bL}^{6}\right)$ was prepared in the laboratory [14], and 5, 11, 17, 23, 29, 35, 41,47-octabutyl $49,50,51,62,53,54,55,56$ octahydroxicalix[8]arene, paratert-butylcalix[8]arene, $\left(\mathrm{H}_{8} \mathrm{bL}^{8}\right)$ was recovered from $\mathrm{H}_{6} \mathrm{bL}^{6}$ purification. Anhydrous chloroform (Aldrich) and isopropanol (Baker or Sigma) were analytical grade and used without further purification for the synthesis. Anhydrous and spectroscopic grade chloroform and acetonitrile from Aldrich were used for $\mathrm{UV}$-visible and luminescence studies. $\mathrm{KBr}$ for IR spectroscopy was purchased from Fluka. 


\section{General techniques}

UV-visible spectrophotometric measurements were carried out with a Perkin-Elmer Lambda 10 spectrophotometer. IR spectra of the compounds in $\mathrm{KBr}$ matrix were recorded on a FTIR Nicolet Nexus spectrometer. ${ }^{1} \mathrm{H}$ NMR spectra were recorded on a Bruker-Avance-300 $\mathrm{MHz}-\mathrm{F}$ spectrometer on sample solutions in $\mathrm{CDCl}_{3} / \mathrm{CD}_{3} \mathrm{OD}$ mixture $(2: 1 \mathrm{v} / \mathrm{v}, 300 \mathrm{~K})$; chemical shifts were referenced to TMS. ESI-MS spectra were measured on a Bruker Daltonics DataAnalysis 3.2 esquire6000 spectrometer in chloroform-methanol mixture $(1: 1.2 \mathrm{v} / \mathrm{v}, 300$ $\mathrm{K})$. Elemental analysis of calixarenes, $\mathrm{PQ}$ and the paraquat calixarene molecular complexes were performed using a Perkin Elmer model 2400 Series II. C, H and N elements were determined, and acetanilide was used as a reference. Chlorine content in PQ and the molecular complexes was determined by NAA (Nuclear Activation Analysis), using the nuclear reactor TRIGA Mark III of ININ and a Ge/hyperpure solid-state detector coupled to a 2048-channel pulse-height analyzer. $\left({ }^{38} \mathrm{Cl}, \mathrm{t}_{1 / 2}\right.$ $=37.18 \mathrm{~min}$ and $\mathrm{E}=1642 \mathrm{keV}$ ).

The luminescence study in the solid (powder) and solution states $\left(\approx 1 \times 10^{-4} \mathrm{M}\right.$ of the samples in chloroform-acetonitrile mixture $(\mathrm{v} / \mathrm{v}=1: 1.2)$ as well in their frozen solutions at $77 \mathrm{~K}$ was carried out as follows: the samples were put in capillaries of luminescence grade and measured on a Perkin Elmer LS55 Luminescence spectrometer with a Xenon lamp. Emission and excitation spectra in fluorescence and phosphorescence modes were recorded at $293 \mathrm{~K}$ (room temperature) and in phosphorescence mode at $77 \mathrm{~K}$. Excitation and emission slits between 7 and 10, and emission filters of 290 and $350 \mathrm{~nm}$ were used to eliminate spurious bands. Their luminescence lifetimes were measured in powder and frozen solutions at $77 \mathrm{~K}$.

\section{Synthesis and characterization of paraquat calixarene molecular complexes}

In a three-necked round bottom flask containing the corresponding amount for $0.1 \mathrm{mmol}$ of each calixarene $(97.33 \mathrm{mg}$ for $\mathrm{H}_{6} \mathrm{bL}^{6}$ and $129.6 \mathrm{mg}$ for $\mathrm{H}_{8} \mathrm{bL}^{8}$ ), $35 \mathrm{~mL}$ of chloroform was added to dissolve the calixarenes. A reflux column with a drying tube containing silica gel with indicator of humidity was attached to one neck. An addition funnel which contained the corresponding amount of PQ $(25.77 \mathrm{mg})$ for $0.1 \mathrm{mmol}$, suspended in $25 \mathrm{~mL}$ of isopropyl alcohol was attached to the second neck. The reaction flask was heated in a silicon oil bath at $50^{\circ} \mathrm{C}$; then the PQ solution was added dropwise. Small amounts of chloroform were added through the third neck in order to maintain the solvent level. The reaction mixture was heated and stirred for $24 \mathrm{~h}$ under anhydrous and dark conditions. The progress of $\mathrm{PQ}-\mathrm{H}_{6} \mathrm{bL}^{6}$ and $\mathrm{PQ}-\mathrm{H}_{8} \mathrm{bL}^{8}$ reactions was monitored by UV-visible spectrophotometry, which permitted the determination of the reaction time. Once the reaction ended, the mother liquor was refrigerated for $24 \mathrm{~h}$ and then stored at room temperature $\left(20^{\circ} \mathrm{C}\right)$; the solid was separated by centrifugation and dried under vacuum $(\sim 133.322 \mathrm{mPa}$ and $\left.80^{\circ} \mathrm{C}\right)$. The slightly yellowish isolated paraquat calixarene compounds were kept in silica gel to protect them from the environment. These, as the starting materials, were analysed by UV-visible spectrophotometry, IR spectroscopy, ${ }^{1} \mathrm{H}$ NMR, ESI-MS, elemental analysis and NAA. Anal. Calcd. for $\mathrm{C}_{79} \mathrm{H}_{101} \mathrm{O}_{7} \mathrm{~N}_{2} \mathrm{Cl}_{5},(1367.95 \mathrm{~g} / \mathrm{mol})$, compound 1, (\%): C, 69.36; H, 7.44; N, 2.05; Cl,12.96. Found: C, 69.69; H, 7.87; N, $1.73 ; \mathrm{Cl}, 13.25$. Yield $=62 \%$. For $\mathrm{C}_{100} \mathrm{H}_{128} \mathrm{O}_{9} \mathrm{~N}_{2} \mathrm{Cl}_{2},(1573.03$ $\mathrm{g} / \mathrm{mol}$ ), compound 2: C, 76.36; H, 8.20; N, 1.78; Cl, 4.51; Found: C, 76.56; H, 8.46; N, 1.38; Cl, 4.59. Yield $=81 \% .{ }^{1} \mathrm{H}$ NMR (ppm) $\mathrm{CDCl}_{3} / \mathrm{CD}_{3} \mathrm{OD}(\mathrm{v} / \mathrm{v}: 2: 1)$. Compound 1, $\mathrm{C}\left(\mathrm{CH}_{3}\right)_{3}$ : s, 1.26; s, $H$-Aryl: s, 7.16; $\mathrm{CH}_{3}-\mathrm{N}:$ s, $4.55 ; H$ - $\beta$-pyridinium: d, 8.73, 8.71; $H$ - $\alpha$-pyridinium: d, 9.18, 9.16. Compound 2, $\mathrm{C}\left(\mathrm{CH}_{3}\right)_{3}: 1.27,1.26_{\text {sh }}$; H-Aryl: $7.47_{\text {sh }}, 7.211,7.482,7.481$; $\mathrm{CH}_{3}$-N: s, 4.55, 4.54sh; $H$ - $\beta$-pyridinium: d, 8.74, 8.72; $H$ - $\alpha-$ pyridinium: d, 9.18, 9.16. $\mathrm{CD}_{2} \mathrm{Cl}_{2} . \mathrm{H}_{8} \mathrm{bL}^{8}$ : $-\mathrm{CH}_{2^{-}}: \mathrm{s}_{\text {(semi-broad), }}$ 4.38 and 3.53 ; $H$-O-aryl: 9.67; $\mathrm{H}_{6} \mathrm{bL}^{6}$ : $-\mathrm{CH}_{2}-\mathrm{s}$ (broad), $3.66 ; H$ O-aryl: s, 10.29.

\section{Testing the stability in water of the isolated PQ calixarene complexes}

1 (1 mg) and $2(3.5 \mathrm{mg})$ were mixed with $5 \mathrm{~mL}$ of distilled water (DW, pH = 5.44), and $1.3 \mathrm{mg}$ of $\mathbf{1}$ and $3.8 \mathrm{mg}$ of $\mathbf{2}$ with $5 \mathrm{~mL}$ of tap water (TW, $\mathrm{pH}=7.72$ ). Each mixture was shaken at a speed of $230 \mathrm{rpm}$ for $10 \mathrm{~min}$ and centrifuged for $5 \mathrm{~min}$ at $5000 \mathrm{rpm}$ to separate aqueous fractions from solid fractions. However, compd. 2 samples required $10 \mathrm{~min}$ more at 10000 rpm for an adequate separation of the fractions. In all cases, both fractions were analysed. After drying the solid fractions under vacuum $(26.7 \mathrm{mPa})$ at least for $48 \mathrm{~h}$, their IR spectra in $\mathrm{KBr}$ pellets were recorded and UV-visible spectra of their corresponding liquid fractions were measured. Aqueous solutions of PQ at $1 \times 10^{-4} \mathrm{M}$ in de-ionised water and at $\mathrm{pH}$ 3.0, 5.5 and 7.97 were prepared and used as references.

\section{Molecular modelling}

Molecular modelling was performed using CAChe WorkSystem Pro 5.04 program packages for Windows ${ }^{\circledR}$ (Fujitsu Ltd., 2000-2002). $\mathrm{H}_{6} \mathrm{bL}^{6}, \mathrm{H}_{8} \mathrm{bL}^{8}$ and PQ molecules (chemical samples) were built and their geometries optimised by Molecular Mechanic calculations (MM) using Augmented MM3 force field. The latter enables minimisation calculations for square planar, trigonal, bipyramidal and octahedral atoms. Therefore, Augmented MM3 yields an optimum molecular geometry, i.e. a structure with an energy minimum [7e, 14b]. This structure is the basis for calculating the heat of formation of the molecule with an optimum geometry determined by the CAChe MOPAC ((Molecular Orbital Package) application by solving the Schrödinger equation using the semiempirical Hamiltonian PM5 (MOPAC/PM5). The COSMO method contained in MOPAC/PM5 is applied in order to evaluate the solvent effects (water) in the heat of formation of the molecule with optimum geometry. The conformer with the lowest energy (the most stable) is calculated using the CONFLEX procedure [15] once Augmented MM3 has been applied. In 
this paper, for the molecular modelling, the theoretical calculations were carried out in the sequential order: Augmented MM3 /CONFLEX/ Augmented MM3/ MOPAC/PM5 and with solvent effect: Augmented MM3 /CONFLEX/ Augmented MM3/ MOPAC/PM5/COSMO.

Thus, the energy minimum of the optimum molecular structure (Augmented MM3 calculations), the lowest energy of its conformer (CONFLEX calculation), and the energy of the molecule (heat of formation) at a geometry-optimized energy minimum (MOPAC/PM5 and MOPAC/PM5/COSMO calculations) $[7 \mathrm{~d}, \mathrm{e}, 14 \mathrm{~b}]$ were obtained for each chemical sample. The same procedures were followed for calculating the PQ-calixarene molecular structures in order to simulate the formation of the paraquat calixarene complexes. For this purpose, the two pyridinium cations of $\mathrm{PQ}$, the Quats, (Scheme 1) were simultaneously interacted with all the double bonds of the phenyl groups of each calixarene, inducing localised cation- $\pi$ interactions, i.e., each pyridinium (Quat) was anchored in a specific position to the double bond in order to link the substrate to the receptor through the cation $-\pi$ interaction. In each case, the calculated molecules yielding the lowest energy and the lowest heat of formation are those reported here.

From the calculated heat of formation $\left(\mathrm{H}^{*}\right)$ of the reagents (PQ, $\mathrm{H}_{6} \mathrm{bL}^{6}$ and $\mathrm{H}_{8} \mathrm{bL}^{8}$ ) and of the products $\left(\mathrm{PQH}_{8} \mathrm{bL}^{8}\right.$ and $\left.\mathrm{PQH}_{6} \mathrm{bL}^{6}\right)$ an approach to the heat of reaction $(H)$ was estimated for each PQ calixarene molecule, using the formula $H$ $=\mathrm{H}^{*}$ Product $-\sum \mathrm{H}^{*}$ Reactants which is commonly used for calculations of $H$ using experimental heats of formation. These estimated $H$ values were useful for designing the experimental procedure for the synthesis of the complexes which has been described in experimental section.

\section{Acknowledgments}

This study was supported by Conacyt (México), project 36689-E. We thank the technicians of the Department of Chemistry of ININ for their help, Dr. Carol Pérez from UNAM for the ${ }^{1} \mathrm{H}$ NMR measurement of the free calixarenes in $\mathrm{CD}_{2} \mathrm{Cl}_{2}$, and Mr. Claudio Fernández at the Library of ININ for his assistance whenever it was needed.

\section{References}

1. Bromilow, R. H. Pest. Manag. Sci. 2003, 60, 340-349.

2. Dinham, B.; Malik, S. Int. J. Occup. Environ. Health 2003, 9, 4052.

3. Ramasivayam, C.; Thamaraiselvi, K.; Yamuna, R. T. Pestic. Sci. 1994, 41, 7-12.

4. Rytwo, G.; Tropp, O.; Serban, C. Appl. Clay Sci. 2002, 20, 273282.

5. a) Monk, P. M. S.; Mortimer, R. J.; Rosseinsky, D. R. Electrochromism: Fundamental and Applications; $\mathrm{VCH}$, Weinheim, 1995. b) Sliwa, W.; Bachowska, B.; Zelichowicz, N. Heterocycles 1991, 32, 2241-2273.
6. a) Gutsche, C. D. Calixarenes revisited, Monographs in Supramolecular Chemistry; The Royal Society of Chemistry, London, 1998; b) Mandolini, L.; Ungaro, R. Calixarene in Action; Imperial College Press, London, 2000, c) Steed, J. W; Atwood, J.L. Supramolecular Chemistry, John Wiley\&Sons., New York, 2000. d) Ma, J. C.; Dougherty, D. A. Chem. Rev. 1997, 97, 1303-1324. e) Gutsche, C. D. Calixarenes, Monographs in Supramolecular Chemistry; The Royal Society of Chemistry, London, 1989.

7. a) Böhmer, V.; Dalla Cort, A.; Mandolini L. J. Org. Chem. 2001, 66, 1900-1902. b) Arnecke, R.; Böhmer, V.; Cacciapaglia, R., Dalla Cort, A.; Mandolini L. Tetrahedron, 1997, 53, 4901-4908. c) Araki, K.; Shimizu, H.; Shinkai, S. Chem. Lett. 1993, 205208. d) Dominik, A.; Roth, H. J.; Schierbaum, K. D.; Göpel, W. Supramol. Sci. 1994, 1, 11-19. e) Meléndez-Alafort, L.; Ramírez, F. de M.; Ferro-Flores, G.; Arteaga de Murphy, C.; Pedraza-López, M.; Hnatowich, D. J. Nucl. Med. Biol. 2003, 30, 605-615.

8. a) Cerichelli, G.; Mancini, G. Langmuir 2000, 16, 182-187. b) Dalla Cort, A.; Mandolini, L.; Mencarelli, P.; Schiaffino L. Supramol. Chem. 2001, 13, 313-323. c) Dalla Cort, A.; Nissinen, M.,; Mancinetti, D.; Nicoletti, E.; Mandolini, L.; Rissanen, K. J. Phys. Org. Chem. 2001, 14, 425-431. d) Bernardo, A. R.; Lu, T.; Córdova, E.; Zhang, L.; Gokel, G. W.; Keifer, A. E. J. Chem. Soc. Dalton Trans. 1994, 529-530. e) Hwang, G. T.; Kim, B. H.; Tetrahedron 2002, 58, 9019-9028.

9. a) Gibson, H. W.; Nagvekar, D. S.; Delaviz, Y.; Bryant, W. S Can. J. Chem. 1998, 76, 1429-1436; b) Huang, F.; Gantzel, P.; Nagvekar, D. S.; Rheingold, A. L.; Gibson, H. W. Tetrahedron Lett. 2006, 47, 7841-7844; c) Han, T.; Chen, C.-F. Org. Lett. 2006, 8, 1069-1072. d) Huang, F.; Gibson, H. W.; Bryant W. S.; Nagvekar, D. S.; Fronczek F. R. J. Am .Chem. Soc. 2003, 125, 9367-9371; e) Bryant, W. S. ; Jones, J. W.; Mason, P. E.; Guzei, I. A.; Rheingold, A. L.; Nagvekar, D. S.; Gibson, H. W. Org. Lett. 1999, 1, 1001-1004. f) Huang, F.; Guzei, I. A.; Jones, J. W.; Gibson, H. W. Chem. Commun. 2005, 1693-1695.

10. a) Arduini, A.; Ciesa, F.; Fragassi, M.; Pochini, A.; Secchi, A. Angew. Chem. Int. Ed. 2005, 44, 278-281. b) Ugozzoli, F.; Massera, C.; Arduini, A.; Pochini, A.; Secchi, A. CrystEngComm, 2004, 6, 327-332. c) Credi, A.; Dumas, S.; Silvi, S.; Ventura, M.; Arduini, A.; Pochini, A.; Secchi, A. J. Org. Chem. 2004, 69, 5881-5887. d) Arduini, A.; Calzavacca, F.; Pochini, A.; Secchi, A. Chem. Eur. J. 2003, 9, 793-799. e) Arduini, A.; Ferdani, R.; Pochini, A.; Secchi, A.; Ugozzoli, F. Angew. Chem. Int. Ed. 2000, 39, 3453-3456. f) Arduini, A.; Bussolati, R.; Credi, A.; Pochini, A.; Secchi, A.; Silvi, S.; Ventura, M. Tetrahedron 2008, 64, 82798286.

11. a) Forster, M.; Girling, R. B.; Hester, R. E. J. Raman Spectrosc. 1982, 12, 36-48. b) Socrates, G. Infrared and Raman Characteristic Groups Frequencies, Tables and Charts, John Wiley and Sons LTD, England, 2005. c) Williams, D. H.; Fleming, I. Spectroscopic Methods in Organic Chemistry, Mc Graw Hill Book Company, UK, Limited. 1980.

12. Gutsche, C. D.; Bauer, L. J. J. Am. Chem. Soc. 1985, 107, 60526059.

13. Bünzli, J.-C. in Lanthanide Probes in Life, Chemical and Earth Sciences. Theory and Practice, Chapter 7, Eds. Bünzli, J.-C. G.; Choppin, G. R. Elsevier Science Publications B.V., Amsterdam, 1989, pp. 219-293.

14. a) Ramírez, F. M.; Varbonov, S.; Cécile, C.; Muller, G.; FatinRouge, N.; Scopelliti, R.; Bünzli, J.-C. G. J. Chem. Soc. Dalton Trans. 2002, 4505-4513 ; b) Ramírez, F. M.; Charbonnière, L.; Muller, G.; Bünzli, J.-C. G. Eur. J. Inorg. Chem. 2004, 23482355.

15. Goto, H.; Osawa, E. J. Chem. Soc. Perkin Trans. 2 1993, 187198. 